\title{
Changing from bevacizumab to ranibizumab in age-related macular degeneration. Is it safe?
}

This article was published in the following Dove Press journal:

Clinical Interventions in Aging

25 November 2009

Number of times this article has been viewed

\author{
Dimitrios A Karagiannis' \\ loannis D Ladas² \\ Efstratios Parikakis' \\ Ilias Georgalas ${ }^{2}$ \\ Athanasios Kotsolis ${ }^{2}$ \\ Giorgos Amariotakis' \\ Vasileios Soumplis' \\ Panagiotis Mitropoulos' \\ 'Ophthalmiatrio Eye Hospital \\ of Athens, Athens, Greece; ${ }^{2}$ First \\ Department of Ophthalmology, \\ Medical School of Athens University, \\ General Hospital of Athens, Athens, \\ Greece
}

Objective: To report our experiences in changing from intravitreal bevacizumab to ranibizumab in age-related macular degeneration (AMD).

Design: Retrospective case series.

Participants and methods: We retrospectively reviewed the records of 34 patients (36 eyes) who were treated with monthly injections of intravitreal bevacizumab for six months and then switched to monthly injections of ranibizumab for 12 months. Best-corrected visual acuity measurements (BCVA), contact lens biomicroscopy, optical coherence tomography (OCT), and fluorescein angiography were performed at the baseline examination and then monthly. Chi-square test was used for statistical analysis.

Results: Following bevacizumab treatment, retinal thickness decreased $(P=0.033)$ while BCVA improved $(P=0.040)$. Changing from bevacizumab to ranibizumab resulted in a transient decrease in BCVA $(P=0.045)$ and an increase in retinal thickness $(P=0.042)$. In addition, three eyes presented with a large subretinal hemorrhage. However, final retinal thickness was better than the initial thickness and the value following the bevacizumab course. No major ocular or systemic side effects were noted.

Conclusions: Ranibizumab was clinically effective in the long term but the change of treatment from bevacizumab to a half-size molecule with less half-life in the vitreous such as ranibizumab contributed to a transient "instability" in the eye which may have triggered the large subretinal hemorrhage. There is insufficient experience reported in the literature in switching from one agent to another. A prospective study with controls is necessary to determine whether it is safe to change from one medication to another.

Keywords: age-related macular degeneration, bevacizumab, ranibizumab, subretinal hemorrhage

\section{Introduction}

Age-related macular degeneration (AMD) is the most common cause of visual loss in patients aged over 65 years. ${ }^{1}$ Neovascular AMD with the development of a choroidal neovascularization $(\mathrm{CNV})$ in the macular area accounts for $80 \%$ of the severe loss of visual acuity due to AMD. ${ }^{2,3}$ Ranibizumab (Lucentis ${ }^{\circledR}$ ), an isotype monoclonal antibody fragment, is a recombinant humanized immunoglobulin $(\operatorname{Ig} 1)$ designed for intraocular use which binds to and inhibits the biologic activity of human vascular endothelial growth factor (VEGF) A. The latter contributes to the development and/or progression of choroidal neovascularization associated with neovascular (wet) AMD. ${ }^{4,5}$ Two-year results of the MARINA study and many other reports support the favorable results of ranibizumab. ${ }^{6-10}$

Bevacizumab (Avastin ${ }^{\circledR}$ ) is a recombinant humanized full-length antibody that binds to all isoforms of VEGF, similar to ranibizumab. For the last two years, bevacizumab
Correspondence: Dimitrios A Karagiannis 5 Dimokratias Ave, Drosia 14572, Greece Tel +302106210043 $\mathrm{Fax}+302103235526$ Email dimitrioskaragiannis@doctors.org.uk 
has been offered as an off-label intravitreal application for the treatment of wet AMD. ${ }^{11-14}$

We report our experience with patients who were treated initially with intravitreal bevacizumab and then switched to ranibizumab for a follow-up period of 18 months.

\section{Participants and methods}

We retrospectively reviewed the records of 34 patients (36 eyes) who were treated initially with intravitreal bevacizumab $1.25 \mathrm{mg} / 0.05 \mathrm{~mL}$ for six months (six-monthly injections) and then switched to ranibizumab $0.5 \mathrm{mg}$ for 12 months (12 monthly injections) when the latter became commercially available in Greece. All patients were suffering from wet AMD and were older than 50 years. All types of neovascularization due to AMD were included in the study. Patients, who had photodynamic therapy with Visudyne ${ }^{\circledR}$ before starting the anti-VEGF treatment, were also included in the study. All patients had best-corrected visual acuity (BCVA) equal or better than 0.1 . There were no eyes with evidence of other ocular disease than AMD during the 18-month follow-up period.

Nonstandarized Snellen BCVA, slit-lamp examination, contact lens biomicroscopy, optical coherence tomography (OCT), and fluorescein angiography (FA) were performed at baseline examination and on a monthly basis. An intravitreal injection was performed every month. In all cases, when changing from bevacizumab to ranibizumab, the first ranibizumab injection was performed one month after the last bevacizumab injection in order to avoid a time interval delay in which the eye was not "covered" by any anti-VEGF treatment.

All injections were performed under standard sterile conditions and topical antibiotics were administered for four days. All patients were examined 3-4 days after the injection.

The study was approved by the hospital ethics committee. All patients signed an informed consent form after detailed explanation of the procedure.

The chi-square test was used for statistical analysis. A $P$-value less than 0.05 was considered to be statistically significant.

\section{Results}

Thirty-four patients (36 eyes) were treated during this 18 -month period. Mean age was 74.28 years. The youngest patient was aged 57 years and the oldest one was aged 89 years. Of the 34 patients, 16 were men $(47.05 \%)$ and 18 were women $(52.95 \%)$.
Initially, and before treatment, all 36 eyes had a mean retinal thickness of $417.81 \mu \mathrm{m}$ and mean BCVA of 0.319 . After the first injection of bevacizumab, the mean retinal thickness was decreased to $328.39 \mu \mathrm{m}(P=0.033)$, which was statistically significant. When the six-month bevacizumab course was completed, the mean retinal thickness had again decreased slightly to $316.19 \mu \mathrm{m}$. BCVA improved initially to 0.477, and showed a slight further improvement (0.494) at the end of six months. Comparing the values before treatment and after the six-month bevacizumab course, the difference was statistically significant both in retinal thickness $(P=0.005)$ and in BCVA $(P=0.040)$. Changing from bevacizumab to ranibizumab resulted in a transient decrease in visual acuity ( 0.494 to $0.436 ; P=0.045$ ) and an increase in retinal thickness (316.19 to $336.08 ; P=0.042$ ), which are both statistically significant parameters. This decrease in visual acuity lasted for a period of two months. The first ranibizumab injection was performed one month after the last bevacizumab injection in order to avoid a time interval in which the eye was not "covered" by any anti-VEGF treatment. Ranibizumab treatment was continued for one year for all eyes.

Final statistically significant results showed that retinal thickness was decreased in comparison to the starting values (417.81 $\mu \mathrm{m}$ to $314.41 \mu \mathrm{m} ; P=0.004)$. In comparison to the value after finishing bevacizumab treatment and before starting ranibizumab treatment and while showing some improvement, this result was not statistically significant (316.19 $\mu \mathrm{m}$ to $314.41 \mu \mathrm{m} ; P=0.09$ ) (Figure 1 ).

Although retinal thickness was significantly decreased at the end of the 18-month follow-up period, visual acuity did not improve as expected. In particular, final BCVA was 0.398. While being better than the initial measurement (0.319), the final BCVA was worse in comparison to that after finishing bevacizumab treatment and before starting ranibizumab treatment (from 0.494 to $0.398 ; P=0.019$ ) (Figure 2).

Following each case in detail, during this 18-month period, we noted these results: Twenty-nine eyes $(80.5 \%)$ showed immediate improvement both clinically (mean retinal thickness, 329.4) and in visual acuity (mean BCVA, 0.517) after the first bevacizumab injection while seven eyes (19.5\%) remained stable (Mean retinal thickness, 324.0; mean BCVA, 0.314 ). On completion of the six-month bevacizumab course, in seven eyes which were stable initially, five showed improvements (mean retinal thickness, $255.0 \mu \mathrm{m}$; mean BCVA, 0.62) while two remained stable (mean retinal thickness, $254.0 \mu \mathrm{m}$; mean BCVA, 0.15). In changing from bevacizumab to ranibizumab, there was a transient decrease in mean BCVA and 


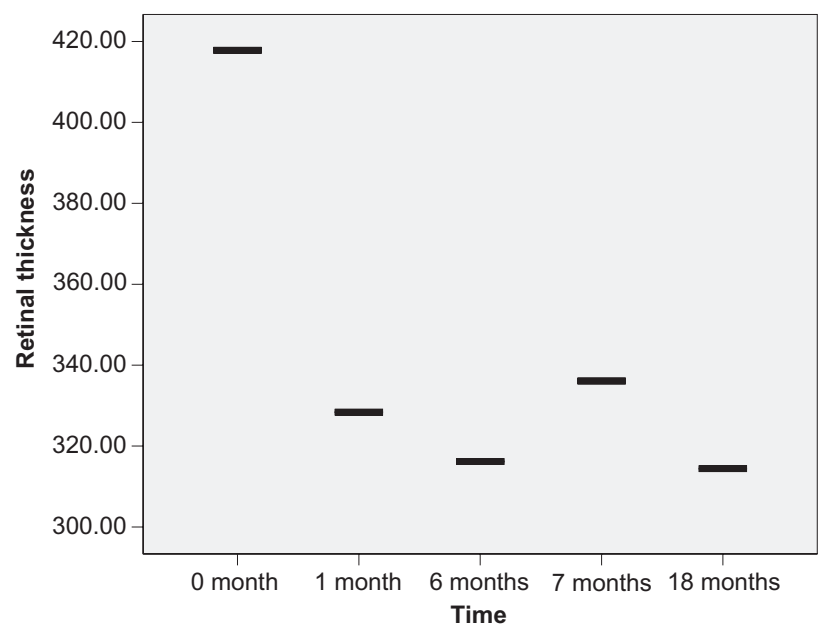

\begin{tabular}{|c|c|c|c|c|c|}
\hline Time & 0 Month & 1 Month & $\mathbf{6}$ Months & 7 Months & 18 Months \\
\hline $\begin{array}{c}\text { Retinal } \\
\text { thickness } \\
(\mu \mathrm{m})\end{array}$ & 417.81 & 328.39 & 316.19 & 336.08 & 314.41 \\
\hline $\begin{array}{c}\text { Standard } \\
\text { deviation }\end{array}$ & 77.648 & 63.402 & 52.306 & 59.177 & 64.645 \\
\hline
\end{tabular}

Figure I Retinal thickness in optical coherence tomography during the 18-month follow-up period.

an increase in mean retinal thickness in OCT. In particular, one eye showed an increase in BCVA and a decrease in retinal thickness, 16 eyes showed deterioration in BCVA and increase in retinal thickness, and 19 eyes showed no change in BCVA with 17 of those having minor increase in retinal thickness while two noted a minor decrease. In addition, three

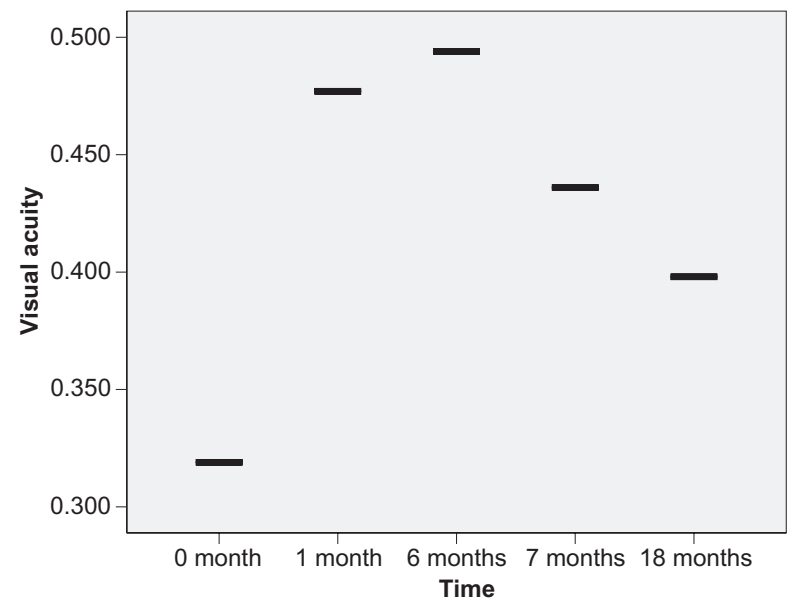

\begin{tabular}{|c|c|c|c|c|c|}
\hline Time & 0 Month & 1 Month & 6 Months & 7 Months & 18 Months \\
\hline Visual acuity & 0.319 & 0.477 & 0.494 & 0.436 & 0.398 \\
\hline $\begin{array}{l}\text { Standard } \\
\text { deviation }\end{array}$ & 0.231 & 0.272 & 0.255 & 0.271 & 0.310 \\
\hline
\end{tabular}

Figure 2 Best-corrected visual acuity during the 18-month follow-up period. patients (three eyes) from the deterioration group presented with a large subretinal hemorrhage within the first month of the first ranibizumab injection and although intravitreal injections of ranibizumab were continued, the hemorrhage expanded further, which resulted in a poor final BCVA. These patients were not on aspirin or other anticoagulant medication and did not have photodynamic therapy prior to the anti-VEGF treatment.

However, after one year of ranibizumab treatment, the final retinal thickness in OCT was improved from the initial measurement and was better than after the six-month course of bevacizumab. BCVA, although improved, did not follow these results. The latter can be explained because, in addition to the three eyes with large subretinal hemorrhage, 13 eyes with longstanding choroidal neovascular lesions were treated with multiple sessions of photodynamic therapy prior to the anti-VEGF treatment. This resulted in a final visual outcome that was worse than expected, although final retinal thickness did decrease.

Finally, no major ocular side effects such as endophthalmitis or retinal detachment were noted. Injection-site reaction and floaters were reported in almost all cases but were innocuous and resolved without treatment. Subconjuctival hemorrhage was noted in only a few cases. In addition, there were no cases of systemic adverse events such as myocardial or cerebral infarction or treatment emerged hypertension and no patient died during the 18-month study.

\section{Discussion}

Ranibizumab (Lucentis ${ }^{\circledR}$ ), an isotype monoclonal antibody fragment, is a recombinant humanized Ig1 designed for intraocular use which binds to and inhibits the biologic activity of human VEGF A. Nearly $95 \%$ of patients with minimally classic or occultc choroidal neovascularization treated with intravitreal injections of ranibizumab lost fewer than 15 letters compared with $62.2 \%$ of patients receiving placebo injections. ${ }^{6}$ Many other reports support these findings. ${ }^{7-10,15}$

Bevacizumab is a recombinant humanized full-length antibody that binds to all isoforms of VEGF, similar to ranibizumab which has been offered as an off-label intravitreal application for the treatment of wet AMD. ${ }^{11-13,16,17}$

There is controversy over the use of ranibizumab and bevacizumab for treating AMD, ${ }^{18}$ which is the leading cause of blindness in people aged older than 65 years. ${ }^{1}$ Although both medications alone show very promising results and are now part of everyday practice, there has been no research documenting the results of change from one medication to another. 
Recently, Stepien and colleagues reported that there were no apparent differences in visual acuity or injection rate in switching from bevacizumab to ranibizumab therapy. ${ }^{19}$

Our study had a longer follow-up period and all patients had monthly injections. Using this protocol there was no time interval between changing anti-VEGF therapies and the eye was "covered" by anti-VEGF treatment during the entire follow-up period of 18 months. In comparison to Stepien and colleagues, ${ }^{19}$ this study showed that switching from bevacizumab to ranibizumab resulted in a transient decrease of visual acuity and an increase of retinal thickness causing a transient "instability" in the eye.

The PIER study showed that reducing monthly injections after the first three months resulted in a decrease of visual acuity. ${ }^{7}$ In our study, we injected bevacizumab monthly for six months followed by injections of ranibizumab monthly for one year. Thus, the decrease of visual acuity cannot be associated with any discontinuation of monthly anti-VEGF therapy.

Although a large subretinal hemorrhage may occur during anti-VEGF treatment without any obvious explanation, ${ }^{20}$ the above mentioned transient "instability" may have triggered the large subretinal hemorrhage. The possibility of subretinal hemorrhage following change from intravitreal bevacizumab to ranibizumab has been reported. ${ }^{21}$ In our three cases, patients were not on aspirin or other anticoagulant treatment and did not have photodynamic therapy prior to the antiVEGF treatment. According to the literature, complications such as retinal epithelial tears are known. ${ }^{22}$ In our cases, OCT covered the entire macular area, and did not show any signs of retinal tear, which could explain such a hemorrhage. It is known that the natural history and the visual outcome of a submacular hemorrhage in AMD are very poor. ${ }^{23}$ However, Stifter and colleagues ${ }^{24}$ reported that intravitreal bevacizumab seems to be a promising therapeutic option in eyes with neovascular AMD and large submacular hemorrhages, with stabilization in BCVA and anatomic improvement. Our patients deteriorated further even although treatment was continued on a monthly basis.

In our study, eyes with longstanding choroidal neovascular lesions were treated with multiple sessions of photodynamic therapy prior the anti-VEGF treatment and had a less satisfactory visual outcome. It is known that photodynamic therapy improves the prognosis of exudative AMD. However, its effectiveness differs among different subtypes of choroidal neovascularization. However, according to the literature, histopathological studies described retinal pigment epithelium alterations and occlusion of choriocappilaris lumina caused by damage to endothelial cells..$^{25,26}$ In our study, after 18 months of follow up, both bevacizumab and ranibizumab proved effective in reducing retinal thickness and controlling the disease. However, in those cases treated with photodynamic therapy prior to the anti-VEGF treatment, the final visual outcome was less satisfactory. The latter can be associated with damage of retinal pigment epithelium and the choriocapillaris by the photodynamic therapy, the long-standing disease, or both.

This study has obvious limitations such as the small number of patients, the nonstandardized visual acuity measurements and that it is retrospective. However, changing from one anti-VEGF agent to another is an aspect of anti-VEGF treatment which requires further investigation.

According to the literature, bevacizumab does not harm retinal function and is well tolerated by ganglion cells and photoreceptors. ${ }^{27-30}$ The molecular size of ranibizumab and bevacizumab and their half-life in vitreous are different. ${ }^{28,29}$

Ranibizumab was clinically effective in the long term in reducing retinal thickness, but the change of treatment from a larger molecule such as bevacizumab to a half-size molecule with less half-life in vitreous such as ranibizumab may have contributed to this transient increase in retinal thickness and decrease in visual acuity. The latter created a transient "instability" in the eye which may have triggered the large subretinal hemorrhage. One possible solution to the change of medication would be to increase the dose of ranibizumab on the month of shifting. A prospective study with large series of patients and controls may be necessary in order to determine whether it is safe to change from one medication to another, or it is preferable to continue treatment with the same anti-VEGF agent for this disease.

\section{Disclosures}

The authors report no proprietary or conflicts of interest in this work.

\section{References}

1. Ambati J, Ambati BK, Yoo SH, Ianchulev S, Adamis AP. Age-related macular degeneration: etiology, pathogenesis, and therapeutic strategies. Surv Ophthalmol. 2003;48(3):257-293.

2. Bressler NM, Bressler SB, Fine SL. Age-related macular degeneration. Surv Ophthalmol. 1988;32(6):375-413.

3. Guyer DR, Fine SL, Maguire MG, Hawkins BS, Owens SL, Murphy RP. Subfoveal choroidal neovascular membranes in age-related macular degeneration. Visual prognosis in eyes with relatively good initial visual acuity. Arch Ophthalmol. 1986;104(5):702-705.

4. Gatto B, Cavalli M. From proteins to nucleic acid-based drugs: the role of biotech in anti-VEGF therapy. Anticancer Agents Med Chem. 2006;6(4):287-301. 
5. Gaudreault J, Fei D, Rusit J, Suboc P, Shiu V. Preclinical pharmacokinetics of Ranibizumab (rhuFabV2) after a single intravitreal administration. Invest Ophthalmol Vis Sci. 2005;46(2):726-733.

6. Rosenfeld PJ, Brown DM, Heier JS, et al. Ranibizumab for neovascular age-related macular degeneration. $N$ Engl J Med. 2006;355(14):1419-1431.

7. Regillo CD, Brown DM, Abraham P, et al. Randomized, doublemasked, sham-controlled trial of ranibizumab for neovascular agerelated macular degeneration: PIER Study year 1. Am J Ophthalmol. 2008;145(2):239-248.

8. Chang TS, Bressler NM, Fine JT, Dolan CM, Ward J, Klesert TR. Improved vision-related function after ranibizumab treatment of neovascular age-related macular degeneration: results of a randomized clinical trial. Arch Ophthalmol. 2007;125(11):1460-1469.

9. Bhatnagar P, Spaide RF, Takahashi BS, et al. Ranibizumab for treatment of choroidal neovascularization secondary to age-related macular degeneration. Retina. 2007;27(7):846-850.

10. Brown MM, Brown GC, Brown HC, Peet J. A value-based medicine analysis of ranibizumab for the treatment of subfoveal neovascular macular degeneration. Ophthalmology. 2008;115(6):1039-1045.e5.

11. Avery RL, Pieramici DJ, Rabena MD, Castellarin AA, Nasir MA, Giust MJ. Intravitreal bevacizumab (Avastin) for neovascular age-related macular degeneration. Ophthalmology. 2006;113(3): 363-372.e5.

12. Rich RM, Rosenfeld PJ, Puliafito CA, et al. Short-term safety and efficacy of intravitreal bevacizumab (Avastin) for neovascular age-related macular degeneration. Retina. 2006;26(5):495-511.

13. Bashshur ZF, Haddad ZA, Schakal A, Jaafar RF, Saab M, Noureddin BN. Intravitreal bevacizumab for treatment of neovascular age-related macular degeneration: a one-year prospective study. Am J Ophthalmol. 2008;145(2):249-256.

14. Buys YM. Bevacizumab: the need for controlled studies to move forward. Can J Ophthalmol. 2007;42(6):789.

15. Singh RP, Kaiser PK. Role of ranibizumab in management of macular degeneration. Indian J Ophthalmol. 2007;55(6):421-425.

16. Melamud A, Stinnett S, Fekrat S. Treatment of neovascular agerelated macular degeneration with intravitreal bevacizumab: efficacy of three consecutive monthly injections. Am J Ophthalmol. 2008;146(1):91-95.

17. Devenyi RG. Editorial: update on the modern management of wet age-related macular degeneration. Can J Ophthalmol. 2006;41(2): $133-138$.
18. Klein RM, Klein RB. Avastin versus Lucentis: ethical issues in treatment of age-related macular degeneration. Retina. 2007;27(9): 1163-1165.

19. Stepien K, Rosenfeld P, Puliafito C, et al. Comparison of intravitreal bevacizumab followed by ranibizumab for the treatment of neovascular age-related macular degeneration. Retina. 2009;29(8):1067-1073.

20. Levine J, Marcus I, Sorenson J, Spaide R, Cooney M, Freund KB. Macular hemorrhage in neovascular age-related macular degeneration after stabilization with antiangiogenic therapy. Retina. 2009;29(8):1074-1079.

21. Karagiannis D, Mitropoulos P, Ladas I. Large subretinal haemorrhage following change from intravitreal bevacizumab to ranibizumab. Ophthalmologica. 2009;223(4):279-282.

22. Bakri SJ, Kitzmann AS. Retinal pigment epithelial tear after intravitreal ranibizumab. Am J Ophthalmol. 2007;143(3):505-507.

23. Scupola A, Coscas G, Soubrane G, Balestrazzi E. Natural history of macular subretinal hemorrhage in age-related macular degeneration. Ophthalmologica. 1999;213(2):97-102.

24. Stifter E, Michels S, Prager F, et al. Intravitreal bevacizumab therapy for neovascular age-related macular degeneration with large submacular hemorrhage. Am J Ophthalmol. 2007;144(6):886-892.

25. Schmidt-Erfurth U, Laqua H, Schlotzer-Schrehard U, Viestenz A, Naumann GO. Histopathological changes following photodynamic therapy in human eyes. Arch Ophthalmol. 2002;120(6):835-844.

26. Schnurrbusch UE, Welt K, Horn LC, Wiedemann P, Wolf S. Histological findings of surgically excised choroidal neovascular membranes after photodynamic therapy. Br J Ophthalmol. 2001;85(9):1086-1091.

27. Kaempf S, Johnen S, Salz AK, Weinberger A, Walter P, Thumann G. Effects of bevacizumab (Avastin) on retinal cells in organotypic culture. Invest Ophthalmol Vis Sci. 2008;49(7):3164-3171.

28. Bakri SJ, Snyder MR, Reid JM, Pulido JS, Ezzat MK, Singh RJ. Pharmacokinetics of intravitreal ranibizumab (Lucentis). Ophthalmology. 2007;114(12):2179-2182.

29. Gaudreault J, Fei D, Beyer JC, et al. Pharmacokinetics and retinal distribution of ranibizumab, a humanized antibody fragment directed against VEGF-A, following intravitreal administration in rabbits. Retina. 2007;27(9):1260-1266.

30. Ladas ID, Karagiannis DA, Rouvas AA, Kotsolis AI, Liotsou A, Vergados I. Safety of repeat intravitreal injections of bevacizumab versus ranibizumab: our experience after 2,000 injections. Retina. 2009;29(3):313-318.
Clinical Interventions in Aging

\section{Publish your work in this journal}

Clinical Interventions in Aging is an international, peer-reviewed journal focusing on evidence-based reports on the value or lack thereof of treatments intended to prevent or delay the onset of maladaptive correlates of aging in human beings. This journal is indexed on PubMed Central, MedLine, the American Chemical Society's 'Chemical

\section{Dovepress}

Abstracts Service' (CAS), Scopus and the Elsevier Bibliographic databases. The manuscript management system is completely online and includes a very quick and fair peer-review system, which is all easy to use. Visit http://www.dovepress.com/testimonials.php to read real quotes from published authors. 